\title{
Determination of Biological Treatability Processes of Textile Wastewater and Implementation of a Fuzzy Logic Model
}

\author{
Harun Akif Kabuk, Yasar Avsar, S. Levent Kuzu, Fatih Ilhan, and Kubra Ulucan \\ Environmental Engineering Department, Yildiz Technical University, Davutpasa Campus, Esenler, 34220 Istanbul, Turkey \\ Correspondence should be addressed to Yasar Avsar; yavsar@gmail.com
}

Received 9 September 2014; Accepted 7 December 2014

Academic Editor: Meenakshisundaram Swaminathan

Copyright ( 2015 Harun Akif Kabuk et al. This is an open access article distributed under the Creative Commons Attribution License, which permits unrestricted use, distribution, and reproduction in any medium, provided the original work is properly cited.

\begin{abstract}
This study investigated the biological treatability of textile wastewater. For this purpose, a membrane bioreactor (MBR) was utilized for biological treatment after the ozonation process. Due to the refractory organic contents of textile wastewater that has a low biodegradability capacity, ozonation was implemented as an advanced oxidation process prior to the MBR system to increase the biodegradability of the wastewater. Textile wastewater, oxidized by ozonation, was fed to the MBR at different hydraulic retention times (HRT). During the process, color, chemical oxygen demand (COD), and biochemical oxygen demand (BOD) removal efficiencies were monitored for 24-hour, 12-hour, 6-hour, and 3-hour retention times. Under these conditions, $94 \%$ color, $65 \%$ COD, and 55\% BOD removal efficiencies were obtained in the MBR system. The experimental outputs were modeled with multiple linear regressions (MLR) and fuzzy logic. MLR results suggested that color removal is more related to COD removal relative to BOD removal. A surface map of this issue was prepared with a fuzzy logic model. Furthermore, fuzzy logic was employed to the whole modeling of the biological system treatment. Determination coefficients for COD, BOD, and color removal efficiencies were $0.96,0.97$, and 0.92 , respectively.
\end{abstract}

\section{Introduction}

Due to their highly colored substance ingredient and hardly treatable characteristic, treatment studies on textile wastewater remain at the top of densely studied topics. As is known, textile wastewater has nonbiodegradable characteristics [13]. In general, textile wastewater is treated by chemical treatment techniques which are expensive and need many chemical applications $[4,5]$.

Due to the fact that textile industry effluents have a wide variety of pollutant parameters, diverse treatment techniques are required. Frequently used treatment processes, considered to be conventional chemical treatment methods, are used to remove COD and color. Alternatively, some of the oxidants presented in Table 1 are thought to be advanced oxidation process chemicals and are particularly used to increase biodegradability of textile wastewater that has high refractory organics. In particular, hydroxyl radicals occur as a result of using those kinds of oxidants and decompose the structure of refractory or resistive organics [6-8].
The ozonation of some industrial wastewaters increases their biological degradability $[9,10]$. Ozone is a very effective substance, especially in color removal [11-14]. The observed COD removal efficiency of ozonation is not as high as color removal efficiencies. In some cases, such as industrial wastewaters having low BOD/COD rates, ozonation is used prior to biological treatment. Simple color removal can be achieved easily at low ozone doses and low operating costs [15]. In the literature, for different $\mathrm{pH}$ values, ozone doses, and durations, COD and color removal ranges vary between 37 and $60 \%$ and between 87 and 99\%, respectively [16-21]. In particular, the effective elimination of toxic substances in textile effluents was observed with ozonation [22, 23].

Natural organic matter can affect the ozone stability in two ways: it can either directly react with ozone ((1) and (2)) or indirectly affect its stability through scavenging of $\mathrm{OH}$ radicals ((3) and (6)) [24]:

$$
\begin{gathered}
\mathrm{O}_{3}+\mathrm{NOM}_{1} \longrightarrow \mathrm{NOM}_{1 \mathrm{ox}} \\
\mathrm{O}_{3}+\mathrm{OM}_{2} \longrightarrow \mathrm{NOM}_{2}^{+\bullet}+\mathrm{O}_{3}{ }^{\cdot-}
\end{gathered}
$$


TABLE 1: Oxidizing potential for conventional oxidizing agents [40].

\begin{tabular}{lc}
\hline Oxidizing agent & Electrochemical oxidation potential, volt \\
\hline Fluorine & 3.06 \\
Hydroxyl radical & 2.80 \\
Ozone & 2.08 \\
Hydrogen peroxide & 1.78 \\
Hypochlorite & 1.49 \\
Chlorine & 1.36 \\
Chlorine dioxide & 1.27 \\
\hline
\end{tabular}

$$
\begin{aligned}
& { }^{\bullet} \mathrm{OH}+\mathrm{NOM}_{3} \longrightarrow \mathrm{NOM}_{3}{ }^{\bullet}+\mathrm{H}_{2} \mathrm{O} \text { or } \mathrm{NOM}_{3}{ }^{\bullet}+\mathrm{OH}^{-} \\
& \mathrm{NOM}_{3}{ }^{\bullet}+\mathrm{O}_{2} \longrightarrow \mathrm{NOM}-\mathrm{O}_{2}{ }^{\bullet} \longrightarrow \mathrm{NOM}_{3}^{+}+\mathrm{O}_{2}{ }^{\bullet-} \\
& \cdot \mathrm{OH}+\mathrm{NOM}_{4} \longrightarrow \mathrm{NOM}_{4} \cdot+\mathrm{H}_{2} \mathrm{O} \\
& \mathrm{NOM}_{4}{ }^{\bullet}+\mathrm{O}_{2} \longrightarrow \mathrm{NOM}_{4}+\mathrm{O}_{2}{ }^{\bullet} \longrightarrow \text { no } \mathrm{O}_{2}{ }^{--} \text {formation }
\end{aligned}
$$

One of the advanced treatment processes applied to domestic or industrial wastewater is membrane bioreactors (MBR) to obtain highly purified water or reuse $[25,26]$. In recent years, the use of MBR systems and their implementation have increased rapidly. MBR systems are defined as biological and physical treatment process such as oxidation and separation of wastewater between biomass and water by membrane equipment [27]. These biological treatments and separation systems are applied either in two parts, aeration and sedimentation tanks in conventional activated sludge process, or in the same tank $[28,29]$. In the MBR process, separation occurs by microfiltration $(0.2 \mu \mathrm{m}$ pore size $)$ or ultrafiltration membrane $(0.01 \mu \mathrm{m}$ pore size) systems. In the course of the treatment time period, a biofilm bulk occurs on the surface of the membranes and occludes the pores of the membranes, thus leading to higher removal efficiencies, in other words, acquiring cleaner water [30-32].

The obtained experimental data set was subjected to artificial intelligence-based modeling. The three influent values (COD, BOD, and color) were utilized to predict the same effluent parameter concentrations. Fuzzy logic, developed by Zadeh, has some advantages over mathematical models where complicated equations are used [33]. Artificial intelligence-based tools are a suitable substitute to conventional methods such as curve fitting due to their speed, robustness, and nonlinear characteristics [34]. Due to its high precision ability and flexibility in use, fuzzy logic has been applied in many of the environmental engineering problems from air pollution to water treatment systems. Research in [35-37] stated that fuzzy logic is one of the methods to apply the expert knowledge to form an advanced control on various treatment processes.

In this study, a two-stage process was developed: an ozonation process followed by an aerobic membrane bioreactor (MBR) to provide the standard Turkish Water Pollution Control Regulations (SKKY) effluent discharge limits in a lab scale. The biodegradation, COD, and color removal performances of this combined system were studied using textile wastewater effluents. At present, the chemical addition processes alone cannot provide SKKY discharge criteria. In contrast to these methods, this two-stage process can meet the SKKY discharge standards. Therefore, this process is eligible as an alternative treatment process.

The main aim of this study is to display the biological treatability of the textile wastewater having low biodegradability and investigate its treatability by an MBR system. To prepare biological degradable wastewater prior to exposure to the MBR system, ozonation was applied to the wastewater. Implementation of the ozonation processes before MBR provides the advantage of acquiring better removal results. Without ozonation, textile wastewater cannot be treated by MBR effectively according to color, BOD, and COD parameters. The experimental results were also applied to the fuzzy logic system. With a short preliminary system demonstration implementation, it is possible to make effluent concentration predictions utilizing influent values with the fuzzy logic model. In addition, the fuzzy logic modeling of this study has the distinction of being first in MBR after biodegradation by ozonation.

\section{Material and Methods}

2.1. Experimental. The samples used in this study were gathered from the effluents of a wool textile plant. The characteristics of wastewater are shown in Table 2.

All of the experimental analyses, especially the initial pollution characteristics of the samples, were analyzed at Yildiz Technical University Environmental Engineering Department laboratory in accordance with Standard Methods [38]. The COD and color were determined using a Hach-Lange DR 5800 brand mark spectrophotometer. The ozonation experiments were carried out for $3 \mathrm{~L}$ samples in a 5 -L cylindrical glass reactor as a batch system. All experiments were performed at room temperature $\left(24 \pm 0.5^{\circ} \mathrm{C}\right)$. Not all of the produced ozone gas reacts with the wastewater. Some parts of the ozone escaped without reacting with the wastewater. Due to health and environmental concerns, the excess ozone was absorbed in gas washing bottles filled with $2 \% \mathrm{w} / \mathrm{w}$ potassium iodide (KI) solution to capture and determine the excess ozone concentration. The ozone concentration was measured by the iodometric method proposed by IOA [39]. According to the ozonation equipment, $32 \mathrm{mg}$ ozone/L air was applied to the wastewater.

Ozone gas was produced by an AZCO VMUS-4 model ozone generator. The system was fed with dried oxygen and ozone was produced by the corona discharge generation process. This system consumes $100 \mathrm{~W}$ electrical energy. Ozone gas was supplied to the bottom of the reactor with an AQUA pipe diffuser system at 0.4 -bar pressure. The main aim of the diffuser system is to obtain fine ozone gas bubbles to mix homogenously with water. All of the connection parts from the generator to the reactor were made of Teflon to resist the ozone's corrosive effect.

In an MBR system, a $4.5 \mathrm{~cm}$ diameter cylindrical ceramic ultrafiltration and a $12.5 \mathrm{~cm}$ height membrane were placed into a $12 \mathrm{~cm}$ diameter $/ 20 \mathrm{~cm}$ height Plexiglas reactor. 
TABLE 2: Textile wastewater characteristics and discharge limits according to SKKY (wool scouring, finishing, weaving, and equivalents).

\begin{tabular}{lccccc}
\hline Parameter & Unit & Raw wastewater & $\begin{array}{c}\text { Effluent of } \\
\text { ozone process }\end{array}$ & $\begin{array}{c}\text { Effluent of } \\
\text { ozone-MBR system }\end{array}$ & SKKY limits \\
\hline COD & $\mathrm{mg} / \mathrm{L}$ & 1600 & 1140 & 380 & 400 \\
Color & $\mathrm{Pt}-\mathrm{Co}$ & 590 & 120 & 10 & 260 \\
BOD & $\mathrm{mg} / \mathrm{L}$ & 544 & 785 & 330 & - \\
\hline
\end{tabular}

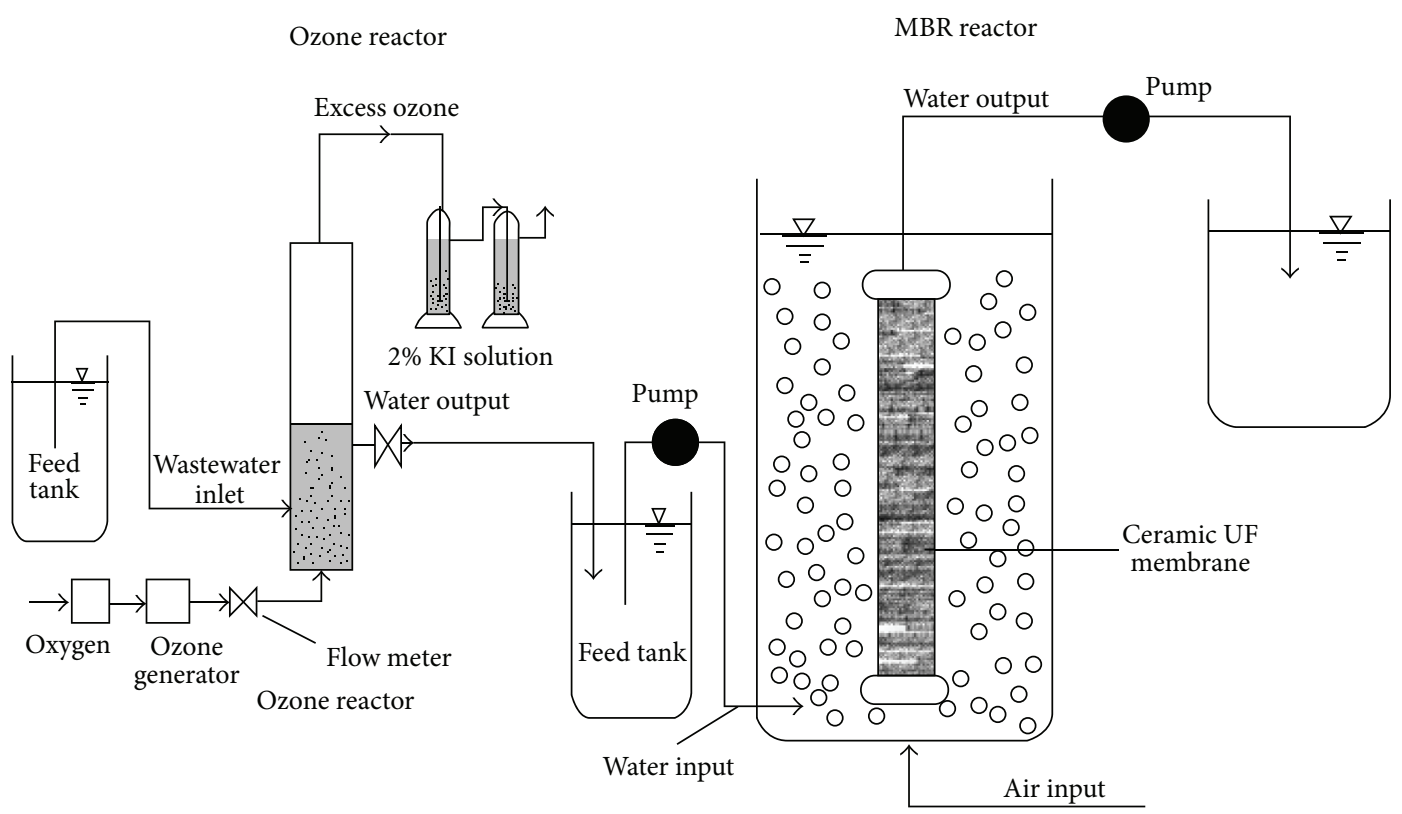

Figure 1: Schematic representation of the ozone and MBR system.

A Watson-Marlow 520 S peristaltic pump was used to vacuum the wastewater. The schematic representation of the study is given in Figure 1.

\section{Results and Discussions}

In the first step of the study, the ozonation process was carried out to increase biodegradability of textile wastewater and to partially remove color. After the ozonation process, the BOD/COD value increased from 0.34 to 0.69 , and $80 \%$ color removal was obtained. The ozonation process was studied at an initial pH 6.1 and 1-hour operation time.

The excess $\mathrm{O}_{3}$ dose that was not used by the wastewater was determined by absorbing $\mathrm{O}_{3}$ into a $2 \% \mathrm{KI}$ solution, and results were as follows: applied $\mathrm{O}_{3}$ dose, $640 \mathrm{mg}$; time, $20 \mathrm{~min} ; \mathrm{O}_{3}$ dose, $64 \mathrm{mg} / \mathrm{min}$; absorbed $\mathrm{O}_{3}$ dose by KI, $45.6 \pm$ $18.5 \mathrm{mg}$; absorbed $\mathrm{O}_{3}$ dose by sample, $594.4 \pm 18.5 \mathrm{mg}$; and $\mathrm{O}_{3}$ concentration for $1 \mathrm{~L}$ sample, $198.1 \pm 6.2 \mathrm{mg} / \mathrm{L}$. Thus, the solubility of $\mathrm{O}_{3}$ was only $198.1 \mathrm{mg} / \mathrm{L}$ at the optimal $\mathrm{O}_{3}$ dose $(32 \mathrm{mg} / \mathrm{L})$ for a $3 \mathrm{~L}$ sample.

The focus of the study was MBR process and thus MBR application lasted for 81 days. Flux values during the experimental study period were examined daily. During an 81-day study period, no serious clogging problem occurred. During the experimental time period there was no need to clean the membrane parts. After 81 days, MBR application was terminated because the discharge standard of the Water
Pollution Control Regulations (SKKY) [41] in Turkey for textile wastewater was achieved and is given in Table 2 . While the flux value was $17.8 \mathrm{~L} / \mathrm{m}^{2}-\mathrm{h}$ at the beginning of the study, this parameter was determined as $8.9 \mathrm{~L} / \mathrm{m}^{2}$-h at the end of the 81 -day time period. Figure 2 shows the flux variation obtained over time.

In the MBR system, removal efficiencies were investigated for different hydraulic retention times (HRT). According to the literature studies on textile wastewater that were examined, a 24-hour HRT was selected as the beginning $[42,43]$. Then, this HRT value was decreased to $12 \mathrm{~h}, 6 \mathrm{~h}$, and $3 \mathrm{~h}$. Once the steady-state condition was reached for each HRT, the analyses were carried out. During the study, no sludge was removed from the reactor and therefore the MBR reactor was operated as endless sludge age.

Considering the whole study, the graphs of COD and BOD removal efficiencies are presented in Figures 3 and 4, respectively. When Figure 3 is investigated, three different curves can be seen. The breaking points indicated in Figure 3 show the changing HRT values. At the beginning of each breaking point, the COD removal rate decreased because of decreasing HRT values. Under the steady-state condition, COD removal efficiency increases over time. Ultimately, the COD removal efficiency was around $65 \%$ when the HRT of the study considered $3 \mathrm{~h}$ as the optimum time.

The organic loading rate (OLR) and, accordingly, the BOD removal efficiencies of the study are given in Figure 4. 


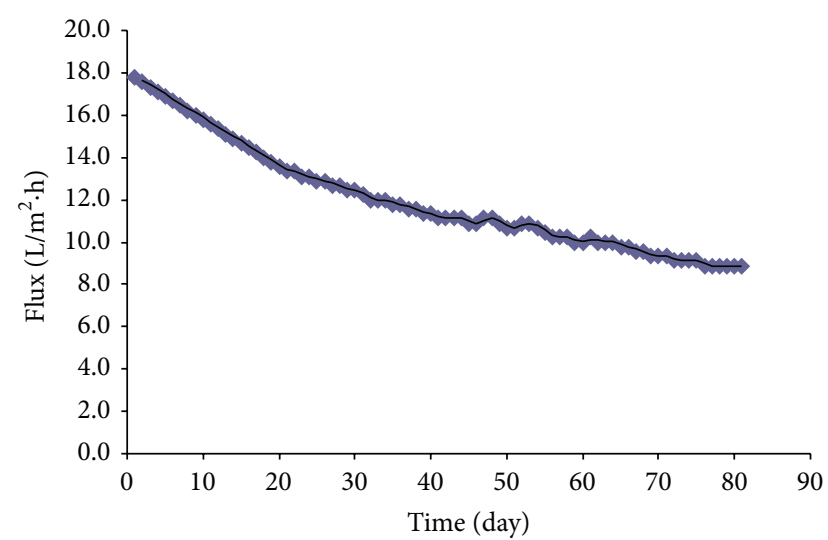

FiguRE 2: Flux variation obtained over time.

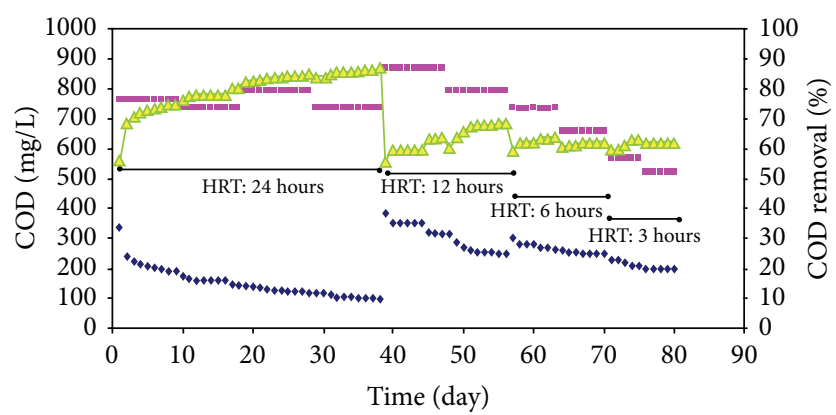

- Effluent COD (mg/L)

- Influent COD $(\mathrm{mg} / \mathrm{L})$

$\triangle$ COD removal (\%)

FIGURE 3: COD removal efficiency.

During the MBR system, various OLR values, ranging between 0.13 and $0.20 \mathrm{~kg} \mathrm{BOD} / \mathrm{m}^{3}$ day, were worked. OLR values decreased with decreasing $\mathrm{HRT}$ values. BOD removal rates changed between $55 \%$ and $92 \%$. BOD removal rates were high for high HRT and OLR values. The BOD removal rate decreased with decreasing HRT and OLR values. At the end of the study, BOD removal efficiency was around 55\%.

3.1. Fuzzy Logic Modeling. Multiple-input and multipleoutput fuzzy logic modeling was applied to the achieved experimental results. A fuzzy logic system consists of four essential components, which are fuzzification, fuzzy rule base, fuzzy inference engine, and defuzzification [44]. The interpretation of the dynamic behavior of the MBR system was accomplished by this four-step modeling algorithm. The fuzzy logic algorithm also provides a transparent relation between the rule bases and the results.

The discrete membership functions or a combination of them can be selected according to the nature of the problem to execute the modeling. Yetilmezsoy chose a combination of triangular and trapezoidal membership functions to predict Fenton's oxidation of anaerobically pretreated poultry manure wastewater [35]. Turkdogan-Aydinol and Yetilmezsoy stated that different types of membership functions such

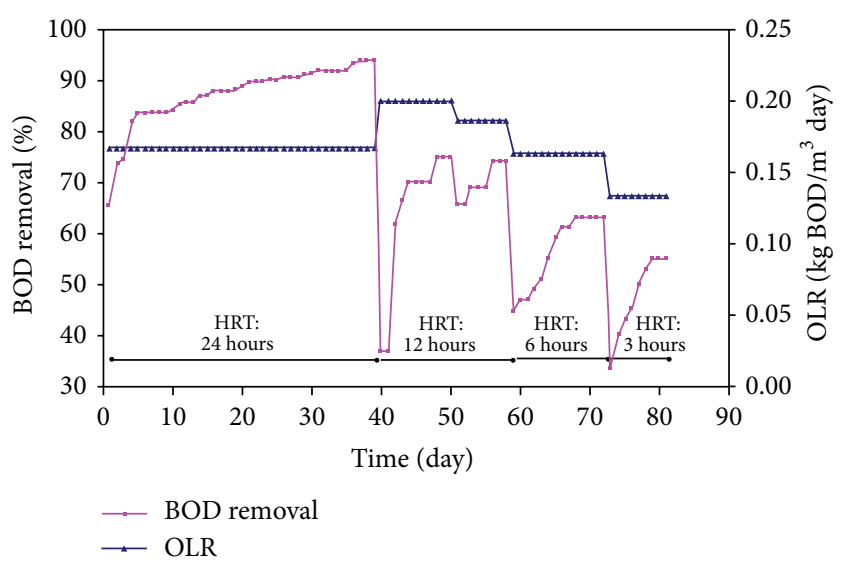

FIGURE 4: BOD removal efficiencies according to the different OLR values.

TABLE 3: The rules used during fuzzy logic process.

\begin{tabular}{|c|c|}
\hline Input variables & Output variables \\
\hline $\begin{array}{l}\text { If } \mathrm{COD} \text { is } \mathrm{H} \text { and } \mathrm{BOD} \text { is } \mathrm{H} \\
\text { and color is } \mathrm{H}\end{array}$ & $\begin{array}{l}\text { Then eCOD is } \mathrm{L} \text { and } \mathrm{eBOD} \text { is } \\
\mathrm{L} \text { and ecolor is } \mathrm{L}\end{array}$ \\
\hline $\begin{array}{l}\text { If } \mathrm{COD} \text { is } \mathrm{M} \text { and } \mathrm{BOD} \text { is } \mathrm{MH} \\
\text { and color is } \mathrm{MH}\end{array}$ & $\begin{array}{l}\text { Then eCOD is } \mathrm{LM} \text { and eBOD } \\
\text { is } \mathrm{LM} \text { and ecolor is } \mathrm{L}\end{array}$ \\
\hline $\begin{array}{l}\text { If COD is } \mathrm{M} \text { and BOD is } \mathrm{M} \\
\text { and color is } \mathrm{MH}\end{array}$ & $\begin{array}{l}\text { Then eCOD is } \mathrm{M} \text { and } \mathrm{eBOD} \text { is } \\
\mathrm{M} \text { and ecolor is } \mathrm{LM}\end{array}$ \\
\hline $\begin{array}{l}\text { If COD is } \mathrm{LM} \text { and } \mathrm{BOD} \text { is } \mathrm{M} \\
\text { and color is } \mathrm{M}\end{array}$ & $\begin{array}{l}\text { Then eCOD is } \mathrm{MH} \text { and } \mathrm{eBOD} \\
\text { is } \mathrm{MH} \text { and ecolor is } \mathrm{M}\end{array}$ \\
\hline $\begin{array}{l}\text { If COD is LM and BOD is LM } \\
\text { and color is LM }\end{array}$ & $\begin{array}{l}\text { Then eCOD is } \mathrm{MH} \text { and eBOD } \\
\text { is } \mathrm{MH} \text { and ecolor is } \mathrm{MH}\end{array}$ \\
\hline $\begin{array}{l}\text { If COD is } \mathrm{L} \text { and BOD is LM } \\
\text { and color is LM }\end{array}$ & $\begin{array}{l}\text { Then eCOD is } \mathrm{H} \text { and eBOD is } \\
\mathrm{MH} \text { and ecolor is } \mathrm{MH}\end{array}$ \\
\hline $\begin{array}{l}\text { If COD is } \mathrm{L} \text { and BOD is } \mathrm{LM} \\
\text { and color is } \mathrm{L}\end{array}$ & $\begin{array}{l}\text { Then eCOD is } \mathrm{H} \text { and } \mathrm{eBOD} \text { is } \\
\mathrm{MH} \text { and ecolor is } \mathrm{H}\end{array}$ \\
\hline $\begin{array}{l}\text { If } \mathrm{COD} \text { is } \mathrm{L} \text { and } \mathrm{BOD} \text { is } \mathrm{L} \text { and } \\
\text { color is } \mathrm{L}\end{array}$ & $\begin{array}{l}\text { Then eCOD is } \mathrm{H} \text { and } \mathrm{eBOD} \text { is } \\
\mathrm{H} \text { and ecolor is } \mathrm{H}\end{array}$ \\
\hline
\end{tabular}

as triangular, trapezoidal, bell-shaped, or other appropriate forms can be used for model prediction [45].

In this study, a combination of Gaussian and trapezoidal type membership functions was utilized to achieve the best fit with Mamdani's method by Matlab. Membership functions for both input and output variables are exhibited in Figure 5.

During the fuzzification of the input data sets, "minimum" operator produced better results than the "prod" operator. Thus, "min" operator was selected as the fuzzy inference operator. Aggregation was accomplished with the "maximum" operator. Defuzzification was completed with "centroid" operator.

Eight rules were formed to start model execution. These rules are shown in Table 3 . Words with the capital letters of $\mathrm{L}$, $\mathrm{M}$, and $\mathrm{H}$ corresponded to low, medium, and high, respectively. The letter "e" was used to indicate effluent pollutant parameters. Input and output variables are connected to each other by an "if-then" expression.

As a consequence of the above selections, determination coefficients of $0.96,0.97$, and 0.92 were achieved for 

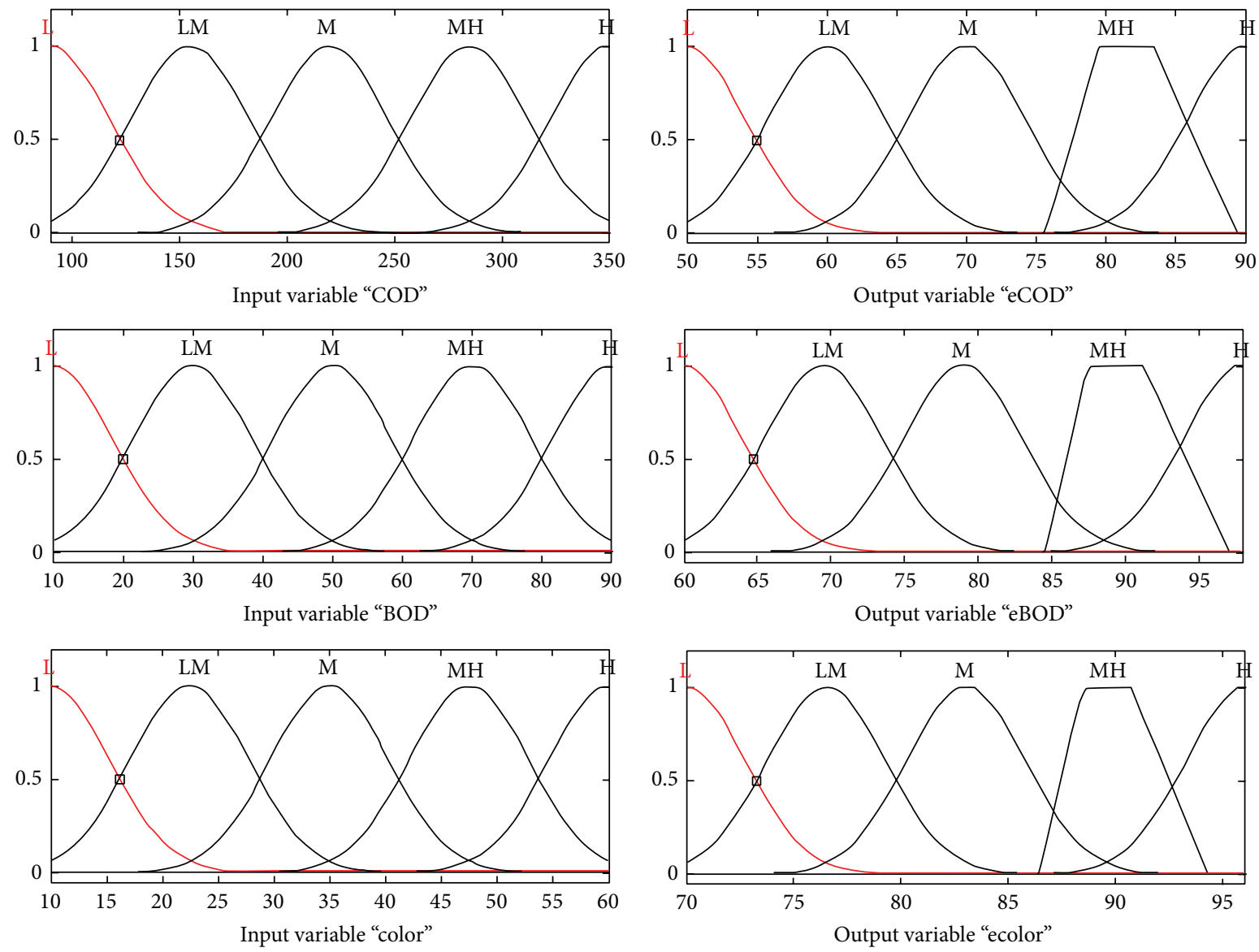

FIGURE 5: Membership functions.

$\mathrm{COD}, \mathrm{BOD}$, and color, respectively. Figure 6 shows the findings and statistical analysis results. COD, BOD, and color observed/predicted results are listed from top to bottom, respectively. On the left hand side of the figure, removal efficiencies are plotted as sample series. In the middle of the figure, observed values are plotted against predicted values to determine determination coefficients. On the right hand side of the figure, box-whisker plots are shown. The horizontal line inside the box refers to the median value, where the top and bottom of the box show $75 \%$ and $25 \%$, respectively. The whiskers extending up and down show the maximum and minimum observed values, respectively.

COD removal rate and BOD removal rate are both effective on color removal efficiency. Multiple linear regression (MLR) was performed to determine the relative weight of COD and BOD removal rates on color removal. Based on 38 pieces of observation data, COD removal is the major factor inducing color removal $(P<0.001)$. However, BOD removal is not statistically significant $(P>0.05)$ in color removal. MLR predicted the coefficient of determination as $86 \%$. This suggests that color forming compounds are hardly biodegradable. Thus, it can be inferred that a chemical preliminary treatment is essential before biological treatment.

A surface map of color removal rate according to influent $\mathrm{COD}$ and $\mathrm{BOD}$ concentrations was prepared by the fuzzy logic modeling results. The prepared map is illustrated in Figure 7.

It can be inferred from Figure 7 that the lower BOD and COD effluent concentrations, the higher color removal efficiencies. As one can expect, color removal rate decreased with the increasing COD and BOD concentrations. The lowest removal rate was observed when the highest BOD concentration and moderate COD concentration were present.

Constitution, strength, and volumetric flow rate of the raw wastewater fluctuate from time to time [37]. That is why modelling study becomes mandatory for optimum operation control. When the opening conditions deviate from the steady-state conditions, modelling results are going to yield the output parameters.

\section{Conclusion}

At the end of the study, the BOD/COD ratio of 0.34 was increased to 0.69 by ozonation as a pretreatment process of the wool textile wastewater. The results of the study were adequate for a 3-hour HRT in an MBR system. Under these conditions, 94\% color, 65\% COD, and 55\% BOD removal efficiencies were obtained in the MBR system. COD, BOD, and color removal performances of the treatment system were modeled by fuzzy logic. The determination coefficient $\left(R^{2}\right)$ 

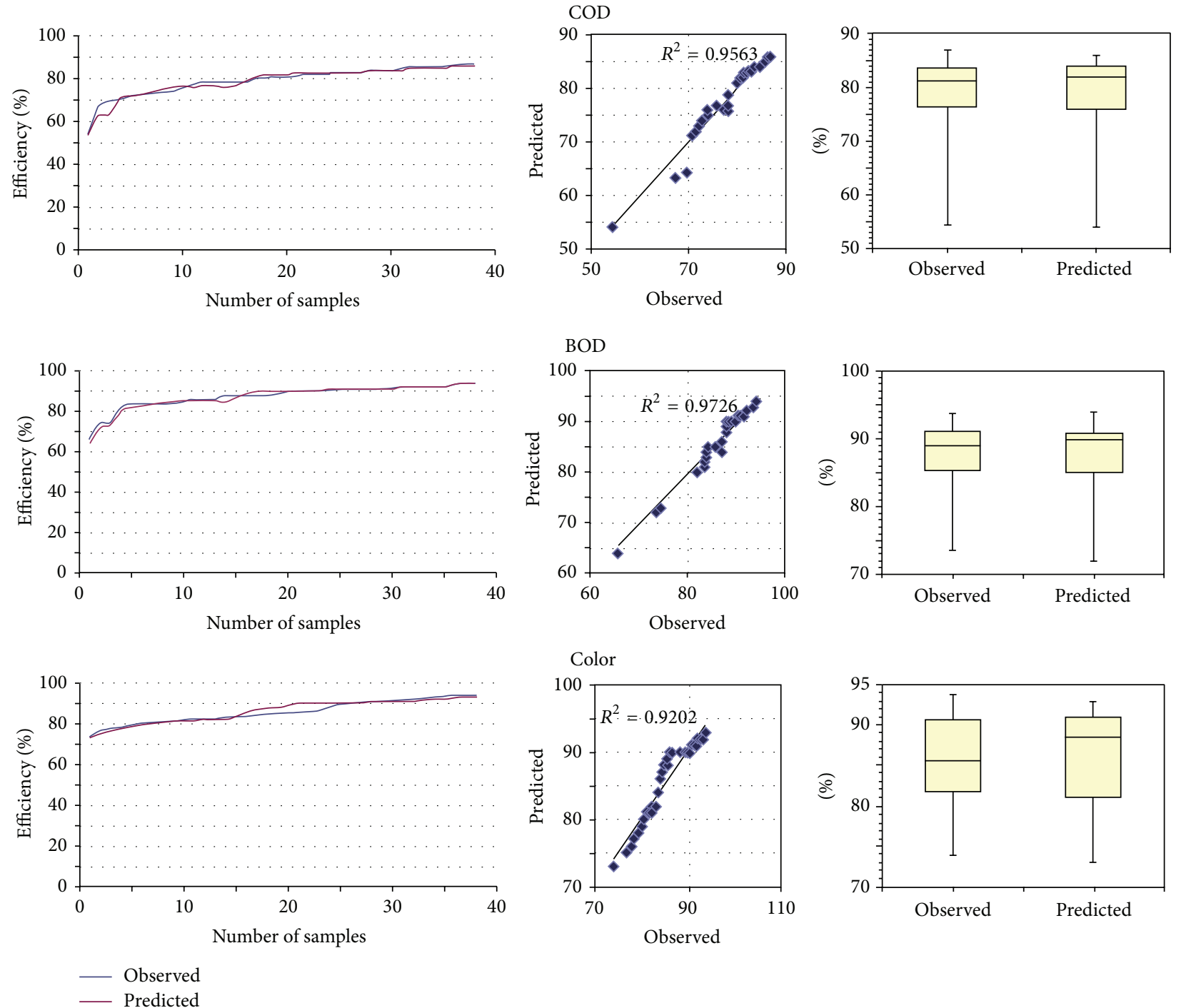

FIGURE 6: Observed-predicted plots.

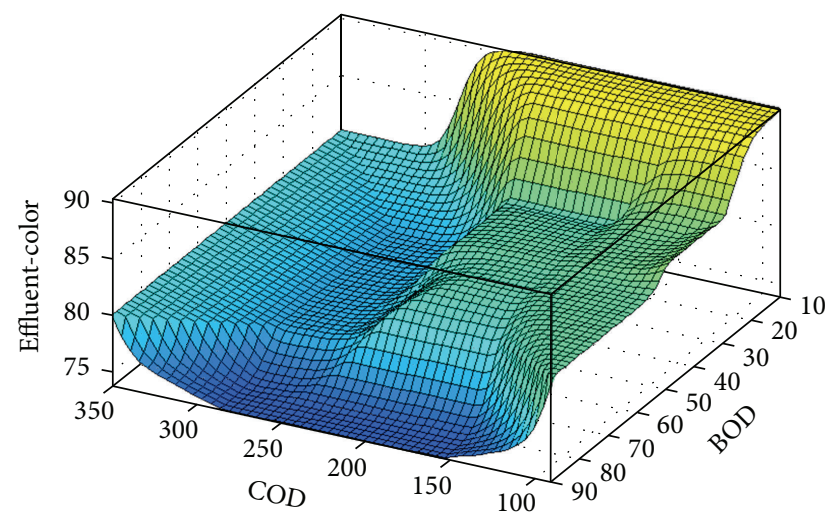

FIGURE 7: Surface map of color removal according to influent values.

was found to be $0.96,0.97$, and 0.92 for COD, BOD, and color, respectively. Multiple linear regressions suggested that the color removal rate is more dependent on the effluent COD value. Results of the estimation model exhibited favorable performance of the data set for predicting the MBR treatment system performance.

\section{Conflict of Interests}

The authors declare that there is no conflict of interests regarding the publication of this paper.

\section{Acknowledgment}

This research was supported by the Yildiz Technical University Scientific Research Projects Coordination Department, Project no. 2009-05-02-KAP01.

\section{References}

[1] Z. Zaroual, M. Azzi, N. Saib, and E. Chainet, "Contribution to the study of electrocoagulation mechanism in basic textile effluent," Journal of Hazardous Materials, vol. 131, no. 1-3, pp. 73-78, 2006. 
[2] O. T. Can, M. Kobya, E. Demirbas, and M. Bayramoglu, "Treatment of the textile wastewater by combined electrocoagulation," Chemosphere, vol. 62, no. 2, pp. 181-187, 2006.

[3] N. O. Yigit, N. Uzal, H. Koseoglu et al., "Treatment of a denim producing textile industry wastewater using pilot-scale membrane bioreactor," Desalination, vol. 240, no. 1-3, pp. 143150, 2009.

[4] S. Aoudj, A. Khelifa, N. Drouiche, M. Hecini, and H. Hamitouche, "Electrocoagulation process applied to wastewater containing dyes from textile industry," Chemical Engineering and Processing: Process Intensification, vol. 49, no. 11, pp. 1176-1182, 2010.

[5] N. Daneshvar, A. R. Khataee, and N. Djafarzadeh, "The use of artificial neural networks (ANN) for modeling of decolorization of textile dye solution containing C. I. Basic Yellow 28 by electrocoagulation process," Journal of Hazardous Materials, vol. 137, no. 3, pp. 1788-1795, 2006.

[6] M. Koch, A. Yediler, D. Lienert, G. Insel, and A. Kettrup, "Ozonation of hydrolyzed azo dye reactive yellow 84 (CI)," Chemosphere, vol. 46, no. 1, pp. 109-113, 2002.

[7] J. Sanz, J. I. Lombraña, A. M. De Luis, and F. Varona, " $U V / \mathrm{H}_{2} \mathrm{O}_{2}$ chemical oxidation for high loaded effluents: a degradation kinetic study of LAS surfactant wastewaters," Environmental Technology, vol. 24, no. 7, pp. 903-911, 2003.

[8] S. K. A. Solmaz, A. Birgül, G. E. Üstün, and T. Yonar, "Colour and COD removal from textile effluent by coagulation and advanced oxidation processes," Coloration Technology, vol. 122, no. 2, pp. 102-109, 2006.

[9] M. Mänttäri, M. Kuosa, J. Kallas, and M. Nyström, "Membrane filtration and ozone treatment of biologically treated effluents from the pulp and paper industry," Journal of Membrane Science, vol. 309, no. 1-2, pp. 112-119, 2008.

[10] Y. Avsar, H. A. Kabuk, U. Kurt, M. Cakmakci, and B. Ozkaya, "Biological treatability processes of textile wastewaters using electrocoagulation and ozonation," Journal of Scientific and Industrial Research, vol. 71, no. 7, pp. 496-500, 2012.

[11] E. Lee, H. Lee, Y. K. Kim, K. Sohn, and K. Lee, "Hydrogen peroxide interference in chemical oxygen demand during ozone based advanced oxidation of anaerobically digested livestock wastewater," International Journal of Environmental Science and Technology, vol. 8, no. 2, pp. 381-388, 2011.

[12] L. Bijan and M. Mohseni, "Novel membrane pretreatment to increase the efficiency of ozonation-biooxidation," Environmental Engineering Science, vol. 25, no. 2, pp. 229-237, 2008.

[13] S. K. A. Solmaz, A. Birgül, G. E. Üstün, and T. Yonar, "Colour and COD removal from textile effluent by coagulation and advanced oxidation processes," Coloration Technology, vol. 122, no. 2, pp. 102-109, 2006.

[14] A. Baban, A. Yediler, D. Lienert, N. Kemerdere, and A. Kettrup, "Ozonation of high strength segregated effluents from a woollen textile dyeing and finishing plant," Dyes and Pigments, vol. 58, no. 2, pp. 93-98, 2003.

[15] L. Szpyrkowicz, C. Juzzolino, and S. N. Kaul, "A comparative study on oxidation of disperse dyes by electrochemical process, ozone, hypochlorite and fenton reagent," Water Research, vol. 35, no. 9, pp. 2129-2136, 2001.

[16] S. Barredo-Damas, M. I. Iborra-Clar, A. Bes-Pia, M. I. AlcainaMiranda, J. A. Mendoza-Roca, and A. Iborra-Clar, "Study of preozonation influence on the physical-chemical treatment of textile wastewater," Desalination, vol. 182 , no. 1-3, pp. 267-274, 2005.
[17] A. Bes-Piá, A. Iborra-Clar, J. A. Mendoza-Roca, M. I. IborraClar, and M. I. Alcaina-Miranda, "Nanofiltration of biologically treated textile effluents using ozone as a pre-treatment," Desalination, vol. 167, no. 1-3, pp. 387-392, 2004.

[18] O. S. G. P. Soares, J. J. M. Órfão, D. Portela, A. Vieira, and M. F. R. Pereira, "Ozonation of textile effluents and dye solutions under continuous operation: influence of operating parameters," Journal of Hazardous Materials, vol. 137, no. 3, pp. 1664-1673, 2006.

[19] N. Azbar, T. Yonar, and K. Kestioglu, "Comparison of various advanced oxidation processes and chemical treatment methods for COD and color removal from a polyester and acetate fiber dyeing effluent," Chemosphere, vol. 55, no. 1, pp. 35-43, 2004.

[20] G. Ciardelli and N. Ranieri, "The treatment and reuse of wastewater in the textile industry by means of ozonation and electroflocculation," Water Research, vol. 35, no. 2, pp. 567-572, 2001.

[21] M. Muthukumar, D. Sargunamani, N. Selvakumar, and J. Venkata Rao, "Optimisation of ozone treatment for colour and COD removal of acid dye effluent using central composite design experiment," Dyes and Pigments, vol. 63, no. 2, pp. 127$134,2004$.

[22] K. Sarayu, K. Swaminathan, and S. Sandhya, "Assessment of degradation of eight commercial reactive azo dyes individually and in mixture in aqueous solution by ozonation," Dyes and Pigments, vol. 75, no. 2, pp. 362-368, 2007.

[23] H. Selcuk, "Decolorization and detoxification of textile wastewater by ozonation and coagulation processes," Dyes and Pigments, vol. 64, no. 3, pp. 217-222, 2005.

[24] U. von Gunten, "Ozonation of drinking water: part I. Oxidation kinetics and product formation," Water Research, vol. 37, no. 7, pp. 1443-1467, 2003.

[25] F. Zanetti, G. de Luca, and R. Sacchetti, "Performance of a full-scale membrane bioreactor system in treating municipal wastewater for reuse purposes," Bioresource Technology, vol. 101, no. 10, pp. 3768-3771, 2010.

[26] E. Atasoy, S. Murat, A. Baban, and M. Tiris, "Membrane bioreactor (MBR) treatment of segregated household wastewater for reuse," Clean-Soil, Air, Water, vol. 35, no. 5, pp. 465-472, 2007.

[27] M. Brik, P. Schoeberl, B. Chamam, R. Braun, and W. Fuchs, "Advanced treatment of textile wastewater towards reuse using a membrane bioreactor," Process Biochemistry, vol. 41, no. 8, pp. 1751-1757, 2006.

[28] J. R. Banu, D. K. Uan, S. Kaliappan, and I. T. Yeom, "Effect of sludge pretreatment on the performance of anaerobic/ anoxic/ oxic membrane bioreactor treating domestic wastewater," International Journal of Environmental Science and Technology, vol. 8, no. 2, pp. 281-290, 2011.

[29] E. Marti, H. Monclús, J. Jofre, I. Rodriguez-Roda, J. Comas, and J. L. Balcázar, "Removal of microbial indicators from municipal wastewater by a membrane bioreactor (MBR)," Bioresource Technology, vol. 102, no. 8, pp. 5004-5009, 2011.

[30] F. Meng, S. R. Chae, H. S. Shin, F. Yang, and Z. Zhou, "Recent advances in membrane bioreactors: configuration development, pollutant elimination, and Sludge Reduction," Environmental Engineering Science, vol. 29, no. 3, pp. 139-160, 2012.

[31] P. Schoeberl, M. Brik, R. Braun, and W. Fuchs, "Treatment and recycling of textile wastewater-case study and development of a recycling concept," Desalination, vol. 171, no. 2, pp. 173-183, 2005. 
[32] Z. Badani, H. Ait-Amar, A. Si-Salah, M. Brik, and W. Fuchs, "Treatment of textile waste water by membrane bioreactor and reuse," Desalination, vol. 185, no. 1-3, pp. 411-417, 2005.

[33] L. A. Zadeh, "Fuzzy sets," Information and Computation, vol. 8, pp. 338-353, 1965.

[34] A. Akkoyunlu, K. Yetilmezsoy, F. Erturk, and E. Oztemel, "A neural network-based approach for the prediction of urban $\mathrm{SO}_{2}$ concentrations in the Istanbul metropolitan area," International Journal of Environment and Pollution, vol. 40, no. 4, pp. 301-321, 2010.

[35] K. Yetilmezsoy, "Fuzzy-logic modeling of Fenton's oxidation of anaerobically pretreated poultry manure wastewater," Environmental Science and Pollution Research, vol. 19, no. 6, pp. 22272237, 2012.

[36] K. Yetilmezsoy and S. A. Abdul-Wahab, "A prognostic approach based on fuzzy-logic methodology to forecast $\mathrm{PM}_{10}$ levels in Khaldiya residential area, Kuwait," Aerosol and Air Quality Research, vol. 12, no. 6, pp. 1217-1236, 2012.

[37] E. Yel and S. Yalpir, "Prediction of primary treatment effluent parameters by Fuzzy Inference System (FIS) approach," Procedia Computer Science, vol. 3, pp. 659-665, 2011.

[38] American Public Health Association (APHA), Standard Methods for the Examination of Water \& Wastewater, American Public Health Association (APHA), Washington, DC, USA, 21st edition, 2005.

[39] Anonymous, "Iodometric method for the determination of ozone in a process gas," IOA Standardization CommitteeEurope 001/87-F, International Ozone Association, Brussels, Belgium, 1987.

[40] G. Tchobanoglous, F. Burton, and H. D. Stensel, Wastewater Engineering: Treatment and Reuse, McGraw-Hill, 4th edition, 2001.

[41] Water Pollution Control Regulation, "Table 10: The discharge standards of textile industry waste water," The Ministry of Forest and Water, 2004.

[42] S.-J. You and J.-Y. Teng, "Anaerobic decolorization bacteria for the treatment of azo dye in a sequential anaerobic and aerobic membrane bioreactor," Journal of the Taiwan Institute of Chemical Engineers, vol. 40, no. 5, pp. 500-504, 2009.

[43] F. I. Hai, K. Yamamoto, F. Nakajima, and K. Fukushi, "Bioaugmented membrane bioreactor (MBR) with a GAC-packed zone for high rate textile wastewater treatment," Water Research, vol. 45, no. 6, pp. 2199-2206, 2011.

[44] J. Jantzen, "Design of fuzzy controllers," Tech. Rep. 98 -E864, Department of Automation, Technical University of Denmark, Lyngby, Denmark, 1998.

[45] F. I. Turkdogan-Aydinol and K. Yetilmezsoy, "A fuzzy-logicbased model to predict biogas and methane production rates in a pilot-scale mesophilic UASB reactor treating molasses wastewater," Journal of Hazardous Materials, vol. 182, no. 1-3, pp. $460-471,2010$. 

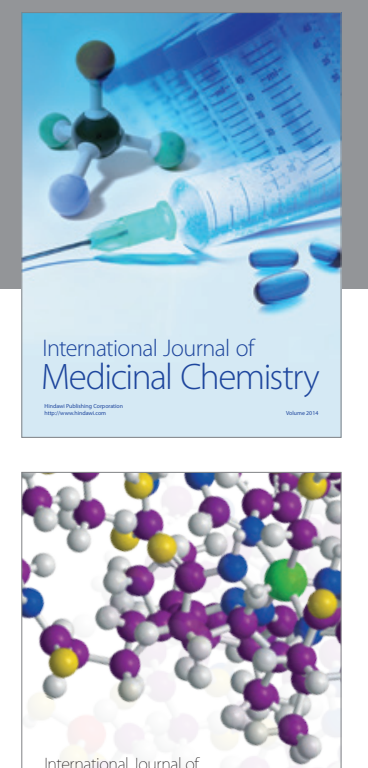

\section{Carbohydrate} Chemistry

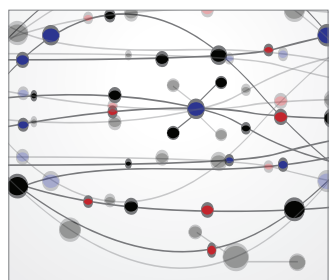

The Scientific World Journal
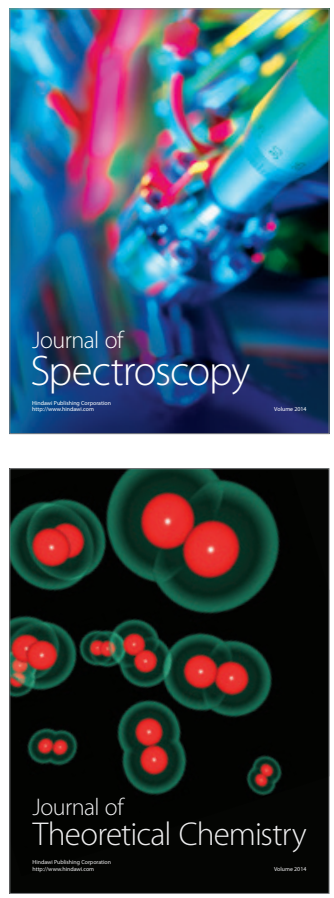
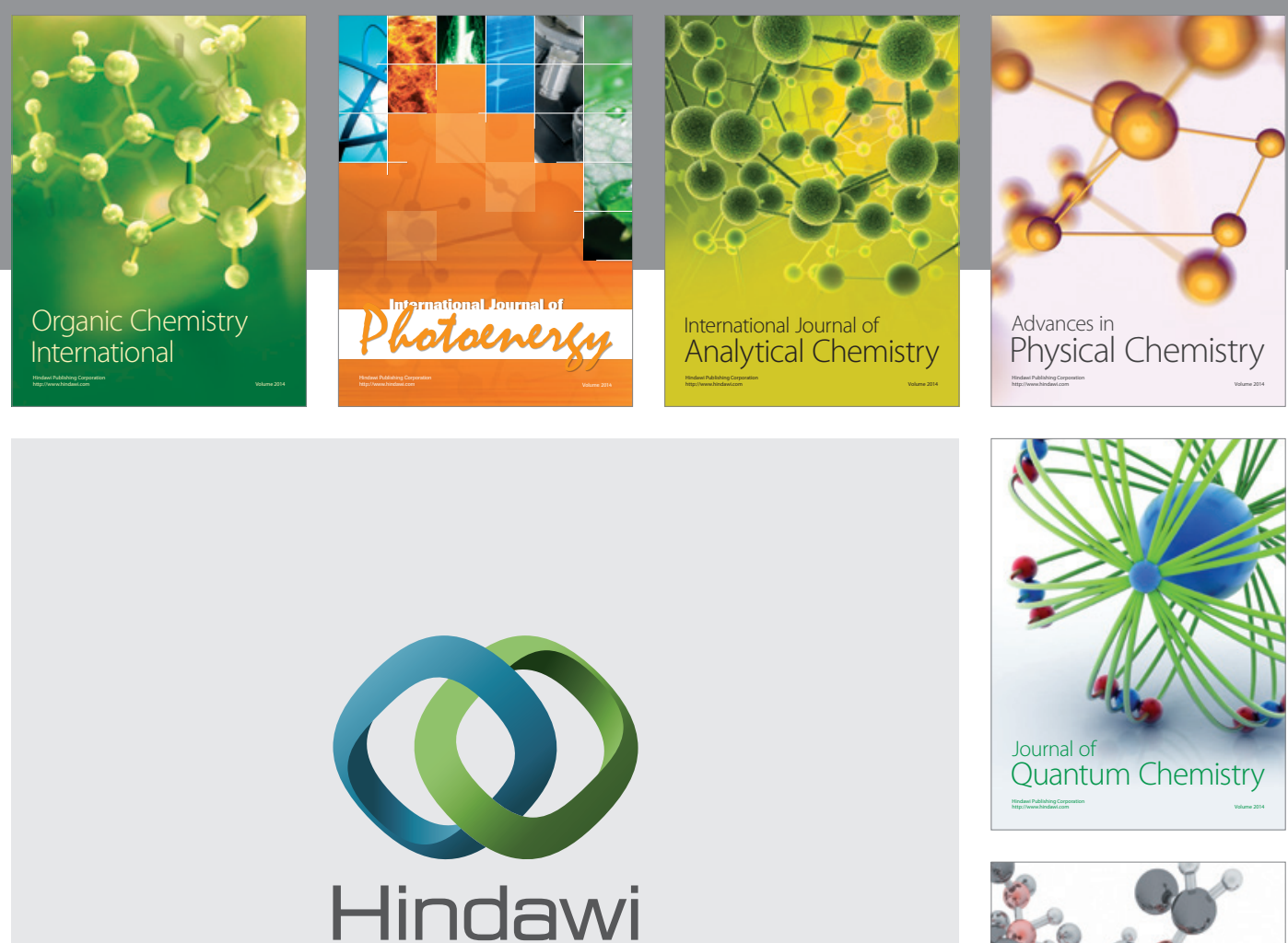

Submit your manuscripts at

http://www.hindawi.com

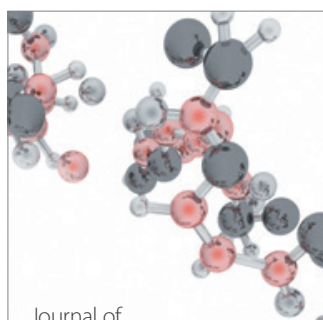

Analytical Methods

in Chemistry

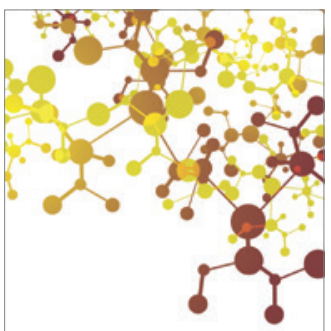

Journal of

Applied Chemistry

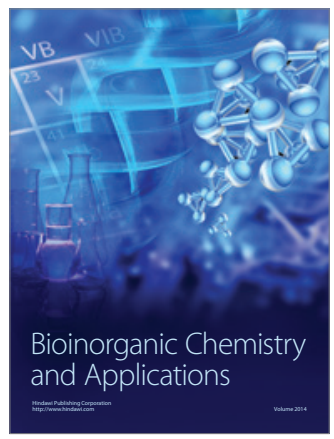

Inorganic Chemistry
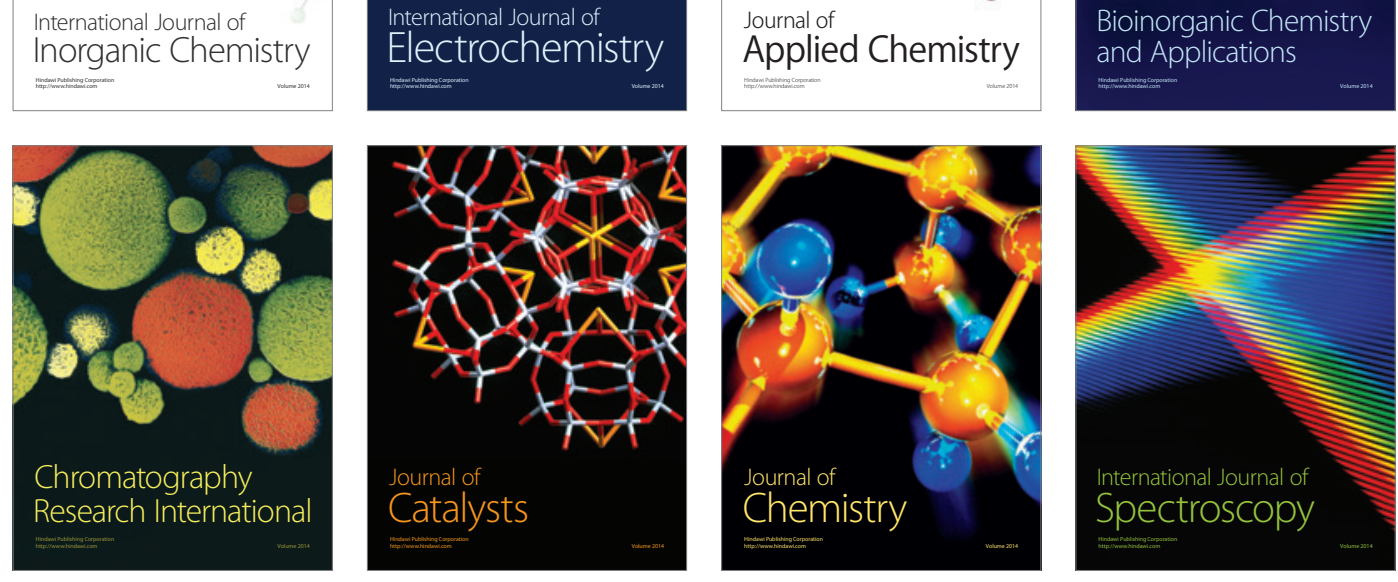